\title{
LEO A CONTINUACIÓN "LA PIEZA OSCURA", POEMA DE ENRIQUE LIHN
}

\section{GRÍNOR ROJO*}

T Eo a continuación "La pieza oscura", el poema de Enrique Lihn, uno Ude los más importantes de la literatura chilena. Empieza así:

1 La mixtura del aire en la pieza oscura, como si el cielorraso hubiera

2 amenazado

3 una vaga llovizna sangrienta ${ }^{1}$.

La pieza está cerrada y carece de luz, estableciéndose de inmediato en el poema de Lihn una contradicción entre un "afuera" manifiesto y un "adentro" que se recoge. En el interior de la pieza, el aire no es homogéneo. No está compuesto por un solo elemento, sino revuelto. A ese aire confuso, en el que se objetiviza un estado de espíritu ídem (por lo que su carácter mismo es incierto: la rima interna de "mixtura" con "oscura" no es casual), lo acompaña una todavía en veremos "vaga llovizna", que obviamente no proviene del "cielo" externo, natural y munificente, sino del "cielorraso" interno, artificial y caprichoso. Ese cielorraso es el mismo que cubre nuestros sueños cada noche, y que aquí les promete a los ocupantes de la "pieza" no agua sino sangre (como si el cielorraso hubiera "amenazado", en el participio al que el verso aísla solitario y amedrentador). De paso, la construcción analógica simple, que asocia una cosa con otra mediante el adverbio "como", por lo general con el ánimo de una mejor visualización del objeto,

\footnotetext{
* Doctor en Filosofía. Académico de la Universidad de Chile, Santiago, Chile.

${ }^{1}$ Enrique Lihn. La pieza oscura. Santiago de Chile. Universitaria, 1963, pp. 15-25. No estando seguro del corte versal en otras ediciones, agradezco a Marianne Leighton el haberme hecho llegar el texto original.
} 
pero tratando de evitar la gran metáfora al estilo del Neruda anterior a las Odas, se repite de ahora e adelante con insistencia, infundiéndole a la marcha del poema un carácter obsesivo. Son tres versos que conforman juntos un preámbulo en el que se fijan la confusión y resolución de la confusión que van a tener lugar luego en el espacio poético.

4 De ese licor inhalamos, la nariz sucia, símbolo de inocencia y de

5 precocidad

6 juntos para reanudar nuestra lucha en secreto, por no sabíamos

7 no ignorábamos que causa;

Comienza el poema a desplegarse en el primero de los tres actos a través de los cuales se plasma su dramatismo: un sujeto plural inhala el aire "mixturado", aprontándose con ello (o reaprontándose) para la "lucha en secreto", como si bebiera un "licor" o como si lo hubiese bebido. El pretérito "inhalamos" [en aquel entonces...] sugiere que la imagen está siendo recuperada por un hablante que es (o fue) miembro del colectivo cuyos avatares él nos refiere, pero habiéndose ubicado a sí mismo en el futuro y caracterizando su lejanía por medio del empleo de un pasado perfecto cuya entera significación se aclarará solo al final. Es un sujeto singular, pero también es un desprendimiento del sujeto plural (es un narrador homodiegético, en la jerga narratológica de Genette, al interior de un poema cuya fraseología prosaica, de cuño eliotesco, a mí me parece evidente). Él es quien desde el porvenir rememora el suceso y describe al grupo al que perteneció alguna vez como integrado por unos niños con la "nariz sucia", aclarándole al lector/la lectora, distanciada, metapoética y por ende irónicamente, que él/ ella debe leer en esa caricatura suya de la "nariz sucia" de sus personajes poéticos una suerte de emblema. No por visual y lexicalizado menos exacto de la niñez turbulenta, es un emblema que él ha reconstruido dentro del paradigma del poema a la manera de un "símbolo" antitético en el que se une la inocencia con la rebeldía precoz. La oscilación cercanía/lejanía de este sujeto singular respecto del teatro de los hechos, que es necesaria para los fines de exaltación y contraexaltación que orientarán el discurso poético, es la que técnicamente facilita el ejercicio de la metapoesía. No el de la antipoesía, en cualquier caso, aunque haya que reconocer un cierto diálogo de Lihn con Parra.

En el presente recordado, el colectivo que en esa circunstancia forman los niños se encuentra listo, porque ellos/ellas se hallan "juntos" y sobre 
todo porque, según se nos informa, están tácitamente dispuestos para "reanudar" un quehacer difícil, que ellos/ellas entienden como una "lucha" por una "causa" que no saben cuál es pero que saben que existe. Se trata, si entendemos el verbo "reanudar" en un sentido amplio, de la continuación de una brega que no solo es la suya propia, ya que hubo otros/as que la pelearon antes y que eran sus pares, aunque lo ignoren.

8 juego de manos y de pies, dos veces villanos, pero igualmente dulces

9 que una primera pérdida de sangre vengada a dientes y uñas o,

10 para una muchacha

11 dulces como una primera efusión de su sangre.

La transgresión de las manos y la de los pies, a la que se nombra con un aforismo popular (me refiero al refrán rimado "juego de manos, juego de villanos", cuya eficacia se duplica en esta circunstancia con el plus del juego de pies), hace explícita la transgresividad, pero sin que se hayan explicitado igualmente las particularidades de la misma. Es la imagen conductora de este primer acto. También se hace sentir con fuerza la hasta ahí pendiente "llovizna sangrienta", aquella que en el segundo verso de la introducción se limitaba a ser la promesa de un peligro y que ahora se baña con un halo iniciático. Porque ahora esa amenaza se actualiza en la primera "pérdida de sangre", que es el punto de arranque de un desarrollo al que en lo sucesivo se figura de dulce y de agraz y cuya significación quedará expuesta a lo largo de los otros dos actos y en un doble epílogo, como luego veremos.

La transgresión que importan los "juegos" se patentiza en la sangre masculina que derraman los niños (esos "dulces villanos") durante sus riñas a bofetadas, que son las pruebas de su ingreso en la adolescencia viril, y es también la de la sangre femenina de las niñas, quienes experimentan simultáneamente su primera menstruación (“'dulces villanas"?, aunque en su caso no haya habido violencia alguna. La existencia de las niñas está aquí atravesada por la pasividad... La masculinidad de este poema me parece a mí al margen de dudas...).

12 Y así empezó a girar la vieja rueda -símbolo de la vida- la rueda

13 que se atasca como si no volara,

14 entre una y otra generación, en un abrir de ojos brillantes y un

15 cerrar de ojos opacos

16 con un imperceptible sonido musgoso. 
La "vieja rueda" debuta y ella es, otra vez distanciada, metapoética e irónicamente, un "símbolo de la vida", con lo que quiero decir que a la frase entre guiones los lectores tenemos que leerla como un cartel brechtiano de advertencia burlona. Con más precisión: la rueda es aquí el vehículo que mueve el devenir que regula la vida histórica en el mundo, así como regula los condicionamientos con que esa vida histórica determina el transcurso de las vidas privadas, con sus épocas de paz, sus crisis y sus cambios, a lo largo de un ciclo que eventualmente se completa dando origen a otro. Pero ocurre que la rueda "de la vida" se ha atascado y detenido de súbito, breve pero también engañosamente, como si en realidad el tiempo "no volara" (segundo refrán popular), como en efecto lo hace, y separando a las generaciones inexorablemente.

17 Centrándose en su eje, a imitación de los niños que rodábamos de

18 dos en dos, con las orejas rojas -símbolos del pudor que saborea

19 su ofensa- rabiosamente tiernos,

20 la rueda dio unas vueltas en falso como en una edad anterior a la

21 invención de la rueda

22 en el sentido de las manecillas del reloj y en su contrasentido.

O, más bien, con su detención la rueda del tiempo les/nos da la impresión, a los participantes en el rito (y a mí en mi calidad de mirón), de dejar abierta la posibilidad de un hiato, en el que tendrá lugar el acontecimiento que se anunció entre los versos nueve y doce, que está en el centro temático del poema, cuya significancia cristaliza en el "hipograma", como quizás lo hubiese denominado Riffaterre, del coming of age, y respecto del cual el todo de la textualidad aspira a captar sus matices ambiguos. Fue entonces cuando se cerraron unos ojos infantiles "opacos", los que no veían aún, y se abrieron los ojos adolescentes, los que asombradamente ven.

De nuevo, la clave del tiempo del suceso la entrega un aforismo popular, en "un abrir y cerrar de ojos", el tercero del poema. Todo esto es inmenso, por cierto, aunque brevísimo, casi imperceptible, semejante al que oye/ve la sinestesia del "sonido musgoso", un sonido en sordina.

Los niños que están dejando de serlo "ruedan". Sabemos los/las lectores/ as de "La pieza oscura" que ruedan entregados frenéticamente a la "lucha de los sexos". Poco después se nos precisará que ruedan por el "suelo". Remedan y sustituyen así los condicionamientos faltantes por el no-giro-dela-rueda-del-tiempo-en-el-mundo, la que ha quedado momentáneamente fuera de combate, rodando-se sobre su propio eje. En ese minuto mágico 
los niños no le obedecen a la rueda, es la rueda la que les obedece a ellos. Están emparejados, "de dos en dos", confirmando la realidad de un acontecimiento que avanza al alimón, conscientes de su potencial subversivo, de la transgresión de la que están siendo protagonistas, si bien temerosos porque intuyen que están desacatando un orden grave.

Y temerosos, además, porque también atisban la sombra perturbadora de un informante que podría estar o quizás ya esté enterado de su desobediencia y denunciándolos en el severo tribunal de los mayores. Las "orejas rojas", que son símbolos "del pudor que saborea la ofensa", también apuntan hacia ese alguien que vigila, un testigo encubierto y soplón. Pero el presentimiento de ese enemigo no anula el frenesí ni la dicha. Ruedan los niños sobre el piso tímidos y eufóricos, "rabiosamente tiernos" (este calificativo en un paralelismo inverso y a la distancia, pero semánticamente equivalente al de "inocencia y precocidad": niños inocentemente precoces), pero sin que ello apague ni por un segundo la luz de alarma que les ha puesto al rojo las orejas, pintadas con ese color que les advierte acerca del testigo atento cuya existencia y lengua mañosas ellos presienten, pero evitan reconocer, tanto como evitan reconocer los signos del grandísimo poder que lo avala.

De ahí que el "pudor que saborea la ofensa" sea un símbolo doble, si leemos bien el decir del hablante ubicado en la postura narrativa que sucede a la del tiempo de los hechos, haciendo uso de un pasado perfecto, según lo marca el uso gramatical: es un ofender que se llevó a cabo entonces, una sola vez, a sabiendas del riesgo que corrían todos de ser descubiertos y castigados, pero estando de acuerdo en arriesgarse a a-cometer el delito, porque así el gusto era mayor que el que podría suscitar un ofender en el que estuviese por completo ausente el placer del peligro. Hubo que sacarle partido a aquel instante propicio, cuando la rueda histórica del mundo como que se había "atascado", dando por eso sus "vueltas en falso". La rueda estaba dando unas vueltas que trataban de retomar su curso de siglos, pero sin conseguirlo, lo que creaba la oportunidad de la transgresión, haciendo o pareciendo que hacía retroceder el tiempo en el "contrasentido" de "las manecillas del reloj", esto es, a un tiempo paradisíaco o presocrático: un tiempo sin tiempo.

23 Por un momento reinó la confusión en el tiempo. Y yo mordí,

24 largamente en el cuello a mi prima Isabel,

25 en un abrir y cerrar del ojo del que todo lo ve, como en una edad

26 anterior al pecado

27 pues simulábamos luchar en la creencia de que esto hacíamos; 
28 creencia rayana en la fe como el juego en la verdad

29 y los hechos se aventuraban apenas a desmentirnos

30 con las orejas rojas.

Sin embargo, el atasco es pura apariencia o, mejor dicho, es apenas una efímera, aun cuando favorable de todas maneras, "confusión en el tiempo". Las "vueltas en falso" de la rueda del mundo dan cuenta del esfuerzo que hacen sus operadores (pero, ¿quiénes son esos operadores?) para salir del atasco, un esfuerzo del tiempo histórico para recuperar su fortaleza, aunque por ahora infructuosamente. El que "todo lo ve" trascendental es el que les ha otorgado a los niños ese respiro o los niños se lo han otorgado ellos/ellas a sí mismos/as, beneficiándose con lo que no es sino un pestañeo descuidado y somnoliento de aquel "que todo lo ve". O, mejor dicho, beneficiándose de la "y" que antecede al verbo "cerrar" en el refrán que habla del tiempo que media entre un "abrir y cerrar de ojos", el cuarto del poema, ya que es ahí precisamente donde se aloja el in-between que le proporciona (proporcionó) al hablante el lapso justo para morder (entonces) el cuello de "mi prima Isabel". Y esta vez el aludido intertextual es el Neruda de "Caballero solo", el de "los primos [que] juegan extrañamente con sus primas" en la primea Residencia. Estos dos versos, el diecinueve y el veinte, nos informan, estimo yo, sobre un cierto clímax.

Y ya lo dije arriba: la avería momentánea de la rueda del mundo sugiere la instalación, también momentánea, de un tiempo paradisíaco o presocrático, un tiempo sin tiempo, el de "una edad anterior al pecado".

Los púberes infractores se sienten habitando ese tiempo o "simulan" que eso es lo que hacen. Se conducen "como" que estuvieran allí, llevados por la "creencia" de que de ese modo están saltando por sobre las convenciones del tiempo histórico, a las que con sus actos les oponen o creen estarles oponiendo la riqueza adánica de un tiempo distinto, la de un no-tiempo sin trabas, cuando se trata connotativamente de una lucha ritual. Actúan con algo parecido a la fe del carbonero. Fe en la existencia de una verdad otra, quizás superior y en todo caso preferible, y para eso se autoengañan, asumiendo las consecuencias por las causas, las superficies por certezas.

El de ellos es un ejercicio poético en verdad, que no es contradictorio y que se les manifiesta como la "más inocente" pero también como la "más peligrosa" de las preocupaciones, según Heidegger percibía en su lectura de Hölderlin. Entre tanto, en el verso con que cierra esta segunda estrofa, las orejas siguen alarmantemente rojas. El alguien que "todo lo ve" preside lo que está sucediendo y tiene para eso a sus informantes desplegados. Por 
su parte los niños, no obstante su denial y debido a su presentimiento de que el Otro castiga (Dios, el padre lacaniano, también podría ser el poeta memorioso que los des-escribe), sospechan que él conoce lo que ellos no conocen o no desean conocer: que todo eso es apariencia, es confusión, es fe voluntariosa y tenaz.

31 Dejamos de girar por el suelo, mi primo Ángel vencedor de Paulina,

32 mi hermana; yo, de Isabel, envueltas ambas

33 ninfas en un capullo de frazadas que las hacía estornudar --olor

34 a naftalina en la pelusa del fruto--.

35 Ésas eran nuestras armas victoriosas y las suyas vencidas

36 confundiéndose unas con otras a modo de nidos como celdas,

37 de celdas como abrazos, de abrazos como grillos en los pies

38 y en las manos.

En la tercera estrofa la actividad de los niños se ha detenido, haciéndole lugar a un intervalo meditabundo y amargo. El tono es aquí opuesto diametralmente al exaltado y triunfalista de la estrofa anterior. La "llovizna sangrienta", que en el primer acto del poema ya había entrado en acción de manera profética, como un desafío aún "vago" a la dicha, y en el segundo como la "primera sangre" de niños y niñas, se materializa y verbaliza ahora en sus virtualidades más aciagas, como el advenimiento seguro de un presente/futuro infeliz. Las niñas, ya muchachas/mujeres, las que rodaron con los muchachos por el suelo, devendrán/han devenido en unas "ninfas" (devenido de "niñas" en "ninfas", con solo un par de fonemas que sugieren un cambio menor, que sin embargo es básico) cuya "pelusa frutal" huele prematura, doméstica y degradadamente ( ¿o es que estamos ante el tiempo de la enunciación?) "a naftalina", en tanto que el futuro de la relación de pareja, o quizás su presente, si es que de veras estamos en el tiempo de la enunciación, se prefigura con la forma de "nidos como celdas", de "celdas como abrazos" y de "abrazos como grillos en los pies y en las manos". Son versos crueles, transidos por la decepción.

39 Dejamos de girar con una rara sensación de vergüenza, sin conseguir

40 formularnos otro reproche

41 que el de haber postulado a un éxito tan fácil.

He ahí el remate del tercer acto, cuando todo lo acontecido previamente se resuelve en una parálisis de la actividad de los niños. El mal sabor en 
sus bocas no es sino la "vergüenza" de la mañana siguiente respecto de una actuación que estuvo desprovista de la magnificencia épica que alguna vez se le imaginó, vergüenza porque todo ello, al fin de cuentas, fue "tan fácil".

42 La rueda daba ya unas vueltas perfectas, como en la época de su

43 aparición en el mito, como en su edad de madera recién

44 carpintereada

45 con un ruido de cantos de gorriones medievales;

46 el tiempo volaba en la buena dirección. Se lo podía oír avanzar hacia

47 nosotros

48 mucho más rápido que el reloj del comedor cuyo tic-tac se enardecía

49 por romper tanto silencio.

50 El tiempo volaba como para arrollarnos con un ruido de aguas

51 espumosas más rápidas en las proximidades de la rueda del molino,

52 con alas de gorriones -símbolos del salvaje orden libre- con

53 todo él por único objeto desbordante

54 y la vida -símbolo de la rueda- se adelantaba a pasar

55 tempestuosamente haciendo girar la rueda a velocidad acelerada,

56 como en una molienda de tiempo, tempestuosa.

En el tercer acto del poema de Lihn la rueda de la vida histórica ha superado su atasco, ya no da vueltas en vano. Eso ocurre al mismo tiempo que los niños han paralizado su propia actividad. Las vueltas de la rueda de la vida histórica son corrientemente "perfectas" y con ellas es perfecto también el regreso del tiempo que marca al centro del escenario, más perfecto aun que el que marcan otros tiempos paralelos, como por ejemplo el familiar del "reloj del comedor".

Los versos cuarenta y dos a cuarenta y siete reconstruyen pretenciosa y velozmente la historia del tiempo triunfante de la historia de Occidente, y pasan de este modo del tiempo clásico, el del origen del mito, al tiempo del Medioevo, que hace suya la rueda reconstruyéndola esta vez con madera (y podemos suponer que en forma de cruz) hasta llegar al tiempo moderno, el de "nosotros". En este último estadio, la rueda será la del molino, o sea la del trabajo. Y el trabajo reemplaza al mito y a la cruz acelerando con su imperio el "volar" de los días, esta vez a impulsos de una fuerza nueva y joven, que actúa con la inquietud espumosa del río y con la libertad de los gorriones, los que -para que usted, estimado lector, no lo olvide- son los "símbolos del salvaje orden libre". 
Acontece en la modernidad una inversión decisiva: la rueda ya no es el símbolo de la vida, sino que la vida es el símbolo de la rueda, pues esta se ha independizado, ha cesado de ser representación y constituyéndose en cambio en presentación, es decir en el instrumento de "lo simbólico" dominante desde el fondo de los fondos. Es ahora el agente de primer plano que transmite una vez más las órdenes de la trascendencia. Y a esta rueda moderna su propio y particular rodaje le importa más que el universal de la humanidad. Casi, casi, podríamos especular que el poema de Lihn preludia aquí un tiempo (¡hoy día tan próximo!) en el que la rueda será capaz de moverse por sí sola habiendo prescindido por completo de nuestros servicios. Resonancias escucho a estas alturas de los molinos premonitorios de Jorge Teillier, tempranamente laboriosos en el pueblo de Lautaro, y, del planteo historiográfico del "Soliloquio del individuo" de Nicanor Parra, escéptico y cínico, afín en algunas esquinas al discurso de Lihn, aunque Lihn se sobreponga y lo supere.

57 Yo solté a mi cautiva y caí de rodillas, como si hubiera envejecido

58 de golpe, presa de dulce, de empalagoso pánico

59 como si hubiera conocido, más allá del amor en la flor de su edad,

60 la crueldad del corazón en el fruto del amor, la corrupción

61 del fruto y luego... el carozo sangriento, afiebrado y seco.

El "soltar" a la "cautiva" y el caer "de rodillas", "como si hubiera envejecido de golpe", es la causa y la consecuencia en que se resume el despliegue de aquello a lo que asistíamos en los versos previos, empezando por el diecinueve, donde se lee "Y yo mordí largamente el cuello de mi prima Isabel", y terminando con la confesión de ese mismo hablante-amante-irreductiblemente masculino, que en el cincuenta y siete cae y, como en el peor de los tangos, se victimiza.

O, más precisamente, he aquí el comienzo del desencanto, el que sucederá al autoengaño de la exaltación y señalando con ello el momento preciso cuando el tiempo del mundo, imparable, agresivo y corrosivo, recupera su dominio. Lo que queda son residuos: "el pánico", el "más allá del amor" y, sobre todo, el "carozo sangriento, afiebrado y seco". Agrego que el leit motiv "sangriento" es el mismo que calificaba a la "llovizna" de los versos introductorios del poema, el que en el primer acto coronaba la "lucha" entre los sexos y que aquí reafirma el cumplimiento del costado atroz de la promesa que se anunció en el comienzo. Primer epílogo: 
62 ¿Qué será de los niños que fuimos?

El discurso poético de "La pieza oscura" ha vuelto hasta la escena de su enunciación: la del sujeto que en el presente rememora, se pregunta e inserta eso en el enunciado que ocupa el primer hemistiquio del verso sesenta y dos. Es el sujeto que desde el futuro busca el sentido de aquel presente que fue $y$ se fue. Pero entonces

Alguien se precipitó a encender

63 la luz, más rápido que el pensamiento de las personas mayores.

Un instante fugaz, brevísimo, pero esencial, que se terminó cuando, ahora en el segundo hemistiquio del mismo verso, "alguien", que no es El Padre que "todo lo ve" sino alguno de sus agentes - un traidor o un cauteloso, puede que uno de los/las primos/as-, "se precipitó a encender la luz".

64 Se nos buscaba ya en el interior de la casa, en las inmediaciones del

65 molino: la pieza oscura como el claro de un bosque.

66 Pero siempre hubo tiempo para ganárselo a los sempiternos

67 cazadores de niños. Cuando ellos entraron al comedor, allí

68 estábamos los ángeles sentados a la mesa

69 ojeando nuestras revistas ilustradas -los hombres a un extremo, las

70 mujeres al otro-

71 en un orden perfecto anterior a la sangre.

Cuando ese "alguien" oprimió el interruptor y la pieza oscura se iluminó "como el claro de un bosque", los niños ya estaban siendo buscados por "los sempiternos cazadores de niños". Pero estos niños no son tontos. Cuando los adultos los encuentran por fin, ellos están quietos, como "ángeles" hipócritas, sentaditos en el hueco de sus hornacinas. Realizan allí solo actividades certificadas, ateniéndose rigurosamente al orden que se les ha impuesto, "los hombres a un extremo, las mujeres al otro", un orden genérico que es "anterior [o posterior] a la sangre". Es esa la misma sangre que en La pieza oscura entraña un peligro siempre, pero que en ocasiones puede constituir también un desborde, un exceso de vitalidad, al modo de la dépense de Bataille, y que en esta escena continúa presente, aunque sobre ella haya caído el tupido velo de la represión. 
72 En el contrasentido de las manecillas del reloj se desatascó la rueda antes

73 de girar y ni siquiera nosotros pudimos encontrarnos

74 a la vuelta del vértigo, cuando entramos en el tiempo

75 como en aguas mansas, serenamente veloces;

76 en ellas nos dispersamos para siempre, al igual que los restos de un

77 mismo naufragio.

Pasó lo que tenía que pasar: cesó el "vértigo", los niños dejaron de serlo, "entraron en el tiempo", el de la-rueda-del-tiempo-histórico-del-mundo, y ni siquiera volvieron a saber el uno del otro. Fue la de ellos/ellas una entrada y un indoloro deslizarse en "aguas mansas". Pero un "naufragio", como quiera que sea, si bien no el naufragio de todos. De ahí que haya en el poema de Lihn un segundo epílogo:

78 Pero una parte de mí no ha girado al compás de la rueda, a favor de

79 la corriente.

80 Nada es bastante real para un fantasma. Soy en parte ese niño que

81 cae de rodillas

82 dulcemente abrumado de imposibles presagios

83 y no he cumplido aún toda mi edad,

84 ni llegaré a cumplirla como él

85 de una sola vez y para siempre.

No es el poeta de "La pieza oscura" uno de los que se resignaron a girar dócilmente, "al compás de la rueda, a favor de la corriente". Algo del niño rebelde sobrevivió en él, un niño que vivió toda su vida asaltado por "imposibles presagios”. El poeta es un niño que dejó de serlo, pero que no llegó ni llegaría a ser adulto. Se apartó de sus primos y de un destino obediente. No es (dejó de ser) el que fue en "la pieza oscura", la de todos, pero tampoco es (fue) un "hombre" como todos, como lo fueron sus primos o como acabaron siéndolo. El poeta es (fue), en vez de eso, un personaje "fantástico", uno a quien "nada" de aquello que los otros apreciaban le pareció lo "bastante real".

\footnotetext{
${ }^{2}$ Cito la segunda definición que da la RAE del "fantasma": "Imagen o idea irreal creada por la imaginación, especialmente la que está impresa en la memoria de forma atormentadora”.
} 